\title{
Validation and Psychometric Evaluation of the COVID-19 Risk Perception Scale (CoRP): a New Brief Scale to Measure Individuals' Risk Perception
}

\author{
Vincenza Capone ${ }^{1}$ (D) Anna Rosa Donizzetti ${ }^{1} \cdot$ Miriam Sang-Ah Park $^{2}$
}

Accepted: 19 September 2021

(c) The Author(s) 2021

\begin{abstract}
The aim of the work was to develop and validate the COVID-19 Risk Perception Scale (CoRP), a brief self-report questionnaire for individuals' perceptions of risk in the COVID19 pandemic. Two studies were conducted in order to evaluate the new scale's psychometric properties. Study 1 included 269 Italian participants $(77.3 \%$ female) to initially test the scale's structure and construct validity. Study 2 involved 1061 (76.2\% female) Italians aged 18 to 80 years old and examined the structure of the scale, construct validity, and age invariance. Exploratory and Confirmatory factor analyses confirmed the one-factor solution, and the structure of the scale was found to be invariant across age groups. The scale also demonstrated a high internal reliability. The CoRP correlated positively with the fear of COVID-19 scale, and low with the Impact of Event and distressing phenomena as measured by GHQ. The present work thus affirms that the CoRP is a valid instrument for measuring individuals' risk perception of COVID-19.
\end{abstract}

Keywords Risk perception · Scale validation · COVID-19 $\cdot$ Mental health $\cdot$ Health promotion $\cdot$ CoRP (Covid-19 Risk Perception Scale)

\section{COVID-19}

During the last few months of 2019 and the first quarter of 2020, a respiratory coronavirus disease (COVID-19) has suddenly become a major worldwide emergency. COVID-19 has affected individuals in 180 countries and on March 11, 2020, it was officially declared a global pandemic (WHO, 2020a). COVID-19 is a novel pathogen and has been characterized by high degrees of uncertainty, especially in its mode of infection and degree of fatality (Ruiu, 2020). With no vaccines or treatments developed specifically for the virus, avoiding the contact was considered the best existing way to prevent the infection in the initial

Vincenza Capone

vincenza.capone@unina.it

1 Department of Humanities, University of Naples "Federico II", Via Porta Di Massa, 180133 Naples, Italy

2 School of Social \& Health Sciences, Leeds Trinity University, Horsforth, Leeds, UK 
months of the pandemic. Other further protective actions, such as frequent handwashing, avoiding touching nose, mouth, and eyes, and covering mouth and nose while coughing and sneezing, and wearing of mask were also encouraged (WHO, 2020b). A series of governmental decisions was introduced to restrict social and economic behavior, resulting in months-long lockdowns of educational and business activities in countries around the world. This has largely changed the life routine of individuals and the way the society in general functions.

Toward the end of the 2020, the vaccination program against COVID-19 started and substantially alleviated the problems related to the spread of the virus. Subsequently, the challenge for the policymakers is to encourage people to receive the vaccine and, at the same time, promote compliance with anti-contrast regulations. A recent study affirmed that as COVID-19 risk perception increased, so did the intention to receive the vaccine (Caserotti et al., 2021). Compliance with the prescribed behavioral norms and the implementation of preventive and protective measures are steered by the perception of risk related to the virus (Capone et al., 2020; Wise et al., 2020). As for flu vaccination, low risk-perception, doubts about the effectiveness of vaccines, and fear of side-effects were the most common reasons for rejection (Lehmann et al., 2014). Perceived risk of infection and precautionary behavior can vary through time, impacting the effectiveness of disease control measures (Caserotti et al., 2021). After all, risk perceptions refer to people's intuitive evaluations of hazards that they are or might be exposed to, including a multitude of undesirable effects that people associate with a specific cause (Rohrmann \& Renn, 2000).

\section{Risk perception and COVID-19}

Risk perception is the subjective judgment that individuals create and hold regarding the characteristics, severity, and way in which a risk is managed and refers to individuals' psychological evaluations of the probability and consequences of an adverse outcome (Sjöberg, 2000). It is a subjective psychological construct that is influenced by cognitive, emotional, social, cultural, and individual variation both between individuals and across countries (van der Linden, 2017). As Slovic (1992, p. 690) stated, "risk does not exist independent of our minds and culture". In his works, Slovic $(1992,2000)$ demonstrated that number of people affected, dread, and knowledge were three important dimensions that could be used to describe risk perception. This approach has provided a solid foundation for describing how individuals orient toward a range of hazards. The epidemic has received broad media attention globally and is subjected to much discussion on social media, contributing to the types of information about the virus and influencing the perception of risk among people.

Risk perception is rightly placed as a core concept in theories explaining for beliefs and behaviors relating to health, such as Health Belief Model and Protection Motivation Theory (Zani \& Cicognani, 2000). The literature has particularly emphasized on the role of risk perception in motivating health protection behaviors generally (Capone \& Petrillo, 2010, 2012; Donizzetti, 2009; Floyd et al., 2000), and also especially during pandemics (Wise et al., 2020). It is known to be a significant determinant of the public's willingness to cooperate and adopt safety behaviors (Dryhurst et al., 2020). Furthermore, public understanding of risk could be a determinant of community mental and physical health and wellbeing (Baldwin et al., 2020; Birley, 2015). This is the case especially during a pandemic, as compliance with recommended precautionary behaviors is not always evident. Considering 
factors influencing behavioral change during outbreaks of infectious diseases is, therefore, necessary. In particular, individuals' assessments of the risk of the disease and the ways in which such assessments lead to the change in behavior is important (Sjöberg, 2000), as this could lead to reducing the spread of the disease.

Research has demonstrated that perceptions of risk for COVID-19 tend to vary across individuals and groups. Recent studies have highlighted that older people estimated the risk of COVID-19 to be less dangerous than younger people, and that women were more concerned about COVID-19 than men (Dryhurst et al., 2020; Gerhold, 2020). University students had the highest perceived threat level towards COVID-19 in comparison to other medical threats (Shabu et al., 2020). In China, social risk judgment was higher and life satisfaction was lower after the declaration of COVID-19 on January 20, 2020 (Li et al., 2020). Davico and colleagues (2020) affirmed that the psychological impact of COVID19 resulted very strong in Italy and up to $30 \%$ of adults and children in the pandemic area were at a high risk for post-traumatic stress disturbances. In a recent study of COVID-19 risk perception (Shabu et al., 2020), participants who have had direct personal experience with the virus were found to perceive more risk compared to those who did not, and people who received information on the virus from family and friends perceived more risk.

As perceiving the risk of being infected has been identified as an important predictor of safety behaviors in the context of COVID-19 (Centers for Disease Control and Prevention 2020), there is a need for developing tools that can assess COVID-19 risk perceptions accurately and effectively. Different tools for measuring individuals' risk perception of COVID-19 were recently developed in countries and regions including Vietnam (Huynh, 2020), China (Dai et al., 2020), Europe (Dryhurst et al., 2020; Gerhold, 2020), and North America (Dryhurst et al., 2020), with each of these studies having come up with ad hoc tools for their research aims. For example, Dai et al. (2020), in a study aimed to investigate the risk perception and immediate psychological state of health workers in the early stage of the COVID-19 epidemic, designed a tool ad hoc composed of 6 questions aimed to investigate the participants' perceived seriousness of the COVID-19 (example item: "Are you worried about getting infected with COVID-19 yourself?"). Dryhurst et al.' (2020) COVID-19 Risk Perception scale covers affective, cognitive, and temporal-spatial dimensions. The index, developed ad hoc for the study, included items capturing participants' perceived seriousness of the COVID-19 pandemic, perceived likelihood of contracting the virus themselves, perceived likelihood of their family and friends catching the virus, and their present level of worry about the virus (example item: "How worried are you personally about the following issues at present?-Coronavirus/COVID-19").

Although the importance of analyzing risk perceptions at pandemic times is thus recognized in many studies, to date, there is little work that has examined the psychometric characteristics of scales measuring perception to be at risk of COVID-19, and there is little agreement or consistency in the scales developed and used in the existing studies. A review of studies highlighted that the risk perception-behavior relationship was stronger for studies that had higher quality risk measures (Brewer et al., 2007), and a validated measure for COVID-19 risk perception that has strong psychometric properties is much needed. 


\section{Aim and hypotheses}

We aimed, therefore, to validate a brief tool, the COVID-19 Risk Perception Scale (CoRP, Italian Version), examining the structure, reliability, convergent, discriminant validity, and invariance across age groups. We hypothesized that the CoRP scale would have a high internal reliability and is one-dimensional. Rapid assessments are efficient methods for collecting information in a short period of time and when it is not possible to implement classical research methodologies as suggested in pandemic.

We hypothesized that CoRP should have good convergent validity, that it would correlate positively with a corresponding measure of Perceived Fear of COVID-19 (Study 1). Literature on past virus outbreaks has underlined the role of fear in exacerbating the harm perception of the infectious disease (Pappas et al., 2009). Referring to COVID-19, fear is inherent in its characteristics and is not completely manageable, especially with an excess of public concern around it (Ahorsu et al., 2020; Cori et al., 2020). The uncertainty and situational control would be strictly connected with the perception of its risk to the self and to the public (Lerner \& Keltner, 2001).

Discriminant validity was assessed by examining the correlation of CoRP scale with measures of negative psychological reactions. We included Perceived Impact of Event as a measure of stress reactions after traumatic events (Study 1) and General Health Questionnaire (GHQ) as a measure of mental distress (Study 2). The concept of impact of events is related to risk perceptions, but the notions are different (Hershey et al., 1994). Understanding the impact of traumatic experiences on the thoughts and behaviors of people is different from their perception to be at risk. While risk perception is the subjective assessment of the probability of the occurrence of a specific type of adversity (Sjöberg, Moen, \& Rundmo 2004), the impact of event refers to the degree of distress a person feels in response to traumatic event. We thus expected that these variables are very different from each other, highlighting low correlations. Likewise, there is no a priori reason to expect that individuals' risk perception would be strongly correlated with general dysfunction. With regards to group invariance, we hypothesized that the functioning of the CoRP items would not differ across the age range.

\section{Construction of the CoRP}

The instrument was developed in line with the methodology of psycho-social research on construction of measurement scales (DeVellis, 2003). We also analyzed the items of the developed scales on risk perception from COVID-19 in the aforementioned studies. Several theories have remarked on the importance of emotion dimension of risk perception, above all, in the first stage of a pandemic (Loewenstein et al., 2001; Schwarz \& Clore 1983). However, the vast majority of literature on risk perception has recommended the inclusion of cognitive dimension which directly or indirectly characterize and influence people's risk perception (Flesia et al., 2020; Slovic, 1987, 2001). This is because cognitive risk perception represents analytical information processing that is slow, cautious and sequential, and requires the use of more cognitive resource. Starting with these considerations and from an analysis of literature on risk perception, we decided to consider the $\operatorname{cog}$ nitive dimension of risk perception, aimed to capture participants' perceived seriousness of the COVID-19 pandemic, perceived likelihood of contracting the virus themselves and 
perceived likelihood of their family catching the virus. Slovic \& Peters (2006) labeled cognitive dimension of the risk perception as the analytic system in which judgments arrived at through the application of logical connections, systematic comparison of evidence and information, and a conscious justification for action. Measurement approaches for this emphasized individuals' identification and assessment of objective, observable properties of a hazard. The cognitive dimension of risk characteristics is associated with the probability and severity of consequences that are assessed from available information (Bonnet et al., 2012).

Relevant and possible items were pooled together by two researchers who were expert in health psychology. After removing items with overlapping content or expressions, 12 items were retained for further evaluation. An expert panel of health and social psychologists then evaluated the 12 items, and 4 items were deleted based on the suggestion from the panel. The retained 8 items were then sent out to a different expert panel (comprising a health education specialist, a social psychologist, and a sociologist) for a review. Four items were further omitted based on the comments from the expert panel. The final 4 selected items investigated individuals' perception of risk to COVID-19 in this study (see Table 1).

Items were assessed on a five-point Likert scale $(1=$ strongly worried; 2 =worried; $3=$ not sure $; 4=$ not too worried $; 5=$ not worried at all), with lower score indicating higher level of concern.

\section{Procedure and statistical analyses (Studies 1 and 2)}

Research participation was subjected to privacy information and consent to the processing of personal data in accordance with the applicable regulations. The data were provided by individuals in Italy within the context of a broader study conducted within their organizations assessing efficacy. The data were collected first in April 2020 (Study 1) and May 2020 (Study 2). Ethical approval was obtained from the Department of Humanities Ethical Committee of Psychological Research prior to commencement of this project. All participants provided informed consent.

In both studies, the items of CoRP were evaluated with regards to variance and frequency distribution as a means to select the appropriate ones to be used in factor analysis. The Kaiser-Meyer-Olkin (KMO) measure of sampling adequacy and Bartlett's test of sphericity were used to test whether the dataset was appropriate for factor analysis. The

Table 1 The selected items of the CoRP scale

\begin{tabular}{lc}
\hline Italian version & English version \\
\hline CoRP_01 - Quanto sei preoccupato di contrarre & CoRP_01 - Are you worried about getting diseased \\
l'infezione da COVID-19? & with COVID-19 yourself? \\
CoRP_02 - Sei preoccupato che i tuoi familiari & CoRP_02 - Are you worried about your family get- \\
possano contrarre l'infezione da COVID-19? & ting infected with COVID-19? \\
CoRP_03 - Sei preoccupato per l'inadeguatezza & CoRP_03 - Are you worried about inadequate \\
delle misure di protezione? & protective measure? \\
CoRP_04 - Sei preoccupato per l'attuale strategia & CoRP_04 - Are you worried about the current \\
di prevenzione e controllo del virus? & grassroots prevention and control strategy? \\
\hline
\end{tabular}


dimensionality of the scale was investigated using exploratory factor analysis. In order to facilitate the interpretation of the factor analysis, we followed the recommendations of Fabrigar et al. (1999) and performed a principal-axis factor analysis with promax rotation (Nunnally \& Bernstein, 1995). For reliability, we used the analysis of internal consistency through covariance between items using Cronbach's alpha. An internal consistency of greater than 0.70 is thought to be necessary for a valid psychological scale (Nunnally \& Bernstein, 1994). In order to test for internal consistency, we calculated the corrected correlation between the score of the item and the total scale.

Confirmatory factor analysis (CFA) was then conducted using the maximum likelihood estimation method to evaluate the underlying structure of items. In order to evaluate the solution, we performed a tau-equivalent model (Steyer, 2001; Traub, 1994), which meant that the error variance for each item was to be different but all of them should equally explain for the true score variance. We took into account various goodness of fit indexes to evaluate the models: chi-square $\left(X^{2}\right)$, root mean square error of approximation (RMSEA), root mean square residual (RMSR), comparative fit index (CFI) and the Tucker-Lewis index (TLI). $X^{2}$ tests the null hypothesis of perfect model fit where the residual covariance equals zero. CFI and TLI values above 0.90 (Bentler, 2005; Byrne, 1994), RMSEA values below or equal to 0.06, and SRMR values equal to or below 0.09 (Hu \& Bentler, 1999) were considered adequate. Relations between the measures were examined using the Pearson product-moment correlations. Statistical significance was set at $\mathrm{p}$-value $<0.05$. Analyses were conducted with SPSS 21.0, and Lisrel 8.51 for CFA.

\section{Study 1: Analyses of the psychometric properties of the initial scale}

\section{Method}

\section{Pre-test sample}

In this study, the questionnaire was administered to 269 university students, $(77.3 \%$ female), ranging in age between 18 and 45 years (mean age $=22.99$ years old, $S D=2.78$ ). All participants were Italian. $70 \%$ of participants declared that in the territory where they live, there were cases of people declared positive for COVID-19, and 9.5\% said they knew them personally.

\section{Measurements and procedures}

A questionnaire was administrated to the participants with three scales and a form. Participants were recruited via e-mail campaigns, social media, and SMS campaigns. All participants involved voluntarily agreed to participate in the data collection procedure during the year 2020 (March-June). They were invited to fill out an online questionnaire connecting to a weblink associated to the Google Forms platform, an online application developed by Google for collecting data online. It was guaranteed to participants that their answers would be confidential and processed anonymously. There was no time limit for answering the questions; nevertheless, the questionnaire was completed in approximately $20 \mathrm{~min}$. The scales were:

1) The CoRP scale; 
Table 2 Mean, Standard deviations, Variance, Asymmetry and Kurtosis of the items $(\mathrm{N}=267)$

\begin{tabular}{llllll}
\hline & Mean & $\begin{array}{c}\text { Standard } \\
\text { deviation }\end{array}$ & Variance & Asymmetry & Kurtosis \\
\hline CoRP_01 & 2.94 & 1.130 & 1.278 & 0.094 & -1.042 \\
CoRP_02 & 2.06 & 1.069 & 1.143 & 0.970 & 0.117 \\
CoRP_03 & 2.27 & 1.020 & 1.040 & 0.682 & -0.076 \\
CoRP_04 & 2.41 & 1.067 & 1.138 & 0.597 & -0.347 \\
\hline
\end{tabular}

Table 3 CoRP. Loading of the items, corrected correlations and reliability of the item $(\mathrm{N}=267)$

\begin{tabular}{llll}
\hline & Factor loading & $\begin{array}{l}\text { Corrected cor- } \\
\text { relation }\end{array}$ & $\alpha$ if deleted \\
\hline CoRP_01 & 0.637 & 0.595 & .79 \\
CoRP_02 & 0.645 & 0.608 & .78 \\
CoRP_03 & 0.859 & 0.711 & .73 \\
CoRP_04 & 0.762 & 0.627 & .77 \\
\hline
\end{tabular}

2) The Fear of Covid (Graffigna et al., 2020) a single item measuring how much individual is afraid of Covid-19. The scale response ranged from 0 (not at all) to 10 (extremely);

3) The Impact of Event Scale-6 (IES-6; Italian Version, Giorgi et al., 2015) includes a total of six items, with two items from each of the three subscales, intrusion, hyperarousal and avoidance. Participants were asked to report their symptoms in the past 15 days on a Likert Scale ranging from 0 (not at all) to 4 (extremely). An example of the items is "In the past 15 days, I felt watchful or on-guard". The internal reliability was $\alpha=0.80$;

4) Socio-demographic information: participants provided information relating to their gender, age and level of education.

\section{Results}

In order to examine item quality and probability of dysfunctional items or polarization, we estimated the variances, means and standard deviations of the four CoRP items. Results shown in Table 2 indicate that all items have a normal distribution regarding the sample's answers. The average score obtained in the CoRP was $2.42(\mathrm{SD}=0.86)$. All item-test correlations were between 0.60 and 0.71 , suggesting good psychometric properties. To further examine item quality, we carried out a correlational analysis between the four items. All of the inter-item correlations in the CoRP were positive and statistically significant $(\mathrm{p}<0.001)$, ranging from $\mathrm{r}=0.37$ to 0.81 .

\section{Analysis of the dimensionality of the instrument}

Bartlett's sphericity test, which was equal to $X^{2}(d f=6, N=267)=508.380, p<0.00$, and the Kaiser-Meyer-Olkin index (KMO) with a result of 0.657 , guaranteed that the correlation matrix was suitable for exploratory factor analysis. One factor with eigenvalues greater than one emerged. It explained $53.54 \%$ of the variance (Table 3). We estimated the scale reliability using the Cronbach alpha index, which was 0.81 . 


\section{Convergent and discriminant validity}

The CoRP converged positively with the Fear of Covid $(r=0.56, p=0.000)$, demonstrating convergent validity. Regarding the discriminating validity, the CoRP correlated positively but very moderately with the Impact of Event $(r=0.37, p=0.000)$.

\section{Study 2: Analysis of the psychometric properties of CoRP}

\section{Method}

\section{Participants}

A convenience sample of 1061 (76.2\% female), ranging in age between 18 and 80 years (mean age $=37.30$ years old, $\mathrm{SD}=14.13$ ) and living in Italy, participated in Study 2 . $73 \%$ of participants declare that in the territory where they live there are cases of people declared positive for COVID-19, and 9.5\% say they know them personally. $41.6 \%$ of participants were graduated. Many $(41.2 \%)$ were married and working $(55.2 \%)$, while others were university students $(29.7 \%)$.

\section{Measurements}

A questionnaire was administrated to participants including the CoRP scale and the General Health Questionnaire-12 and sociodemographic variables. The General Health Questionnaire-12 (GHQ-12; Goldberg, 1992; Italian version by Piccinelli \& Politi, 1993) is aimed at detecting common symptoms which are indicative of the various syndromes of mental disorder. The scale consists of 12 items rating with a 4-point rating scale, ranging from 1 (strongly disagree) to 4 (agree), and the internal reliability, for this study, was $\alpha=0.88$ in this study. An example item is "Have you recently been able to concentrate on whatever you're doing?".

\section{Results}

Analysis of the CoRP individual items indicated that item scores were not skewed, with none of them showing extreme means and close to zero variances (Table 4). The average score obtained in the CoRP was $2.37, \mathrm{SD}=0.834$.

Table 4 Properties of the items on the CoRP scale $(\mathrm{N}=1061)$

\begin{tabular}{llllll}
\hline Item & Mean & $\begin{array}{l}\text { Standard } \\
\text { deviation }\end{array}$ & Variance & Asymmetry & Kurtosis \\
\hline CoRP_01 & 2.79 & 1.109 & 1.231 & 0.274 & -0.789 \\
CoRP_02 & 1.95 & 1.010 & 1.021 & 1.114 & 0.703 \\
CoRP_03 & 2.36 & 1.090 & 1.187 & 0.547 & -0.542 \\
CoRP_04 & 2.38 & 1.097 & 1.202 & 0.537 & -0.588 \\
\hline
\end{tabular}


Table 5 CoRP. Loading of the items, corrected correlations and reliability of the item $(\mathrm{N}=1061)$

\begin{tabular}{llll}
\hline & Factor loading & $\begin{array}{l}\text { Corrected cor- } \\
\text { relation }\end{array}$ & $\alpha$ if deleted \\
\hline CoRP_01 & 0.660 & 0.577 & .73 \\
CoRP_02 & 0.604 & 0.535 & .75 \\
CoRP_03 & 0.809 & 0.667 & .68 \\
CoRP_04 & 0.610 & 0.549 & .74 \\
\hline
\end{tabular}

Table 6 Confirmatory factor models of theories of the latent structure of the CoPR items

\begin{tabular}{|c|c|c|c|c|c|c|c|c|}
\hline Model & $\chi^{2}(\mathrm{df}) ; \mathrm{p}$ & $\begin{array}{l}\text { RMSEA } \\
\text { (90\% C.I.) }\end{array}$ & SRMR & NFI & NNFI & CFI & GFI & AGFI \\
\hline Single factor - congeneric model & $\begin{array}{l}266.54(2) \\
\mathrm{p}<.001\end{array}$ & $\begin{array}{c}0.35 \\
{[0.32-0.39]}\end{array}$ & 0.11 & 0.81 & 0.42 & 0.81 & 0.89 & 0.44 \\
\hline Single factor - tau equivalent & $\begin{array}{l}394.72(5) \\
\mathrm{p}<.001\end{array}$ & $\begin{array}{c}0.27 \\
{[0.19-0.25]}\end{array}$ & 0.12 & 0.95 & 0.70 & 0.75 & 0.84 & 0.97 \\
\hline $\begin{array}{l}\text { Single factor - tau equivalent } \\
\text { (correlation item } 1 \text { and } 2 \text {; item } \\
3 \text { and } 4 \text { ) }\end{array}$ & $\begin{array}{l}37.81(3) \\
\mathrm{p}>.001\end{array}$ & $\begin{array}{c}0.10 \\
{[0.08-0.14]}\end{array}$ & 0.05 & 0.97 & 0.95 & 0.98 & 0.98 & 0.94 \\
\hline Single factor - parallel model & $\begin{array}{l}404.01(8) \\
\mathrm{p}>.001\end{array}$ & $\begin{array}{c}0.22 \\
{[0.31-0.44]}\end{array}$ & 0.12 & 0.73 & 0.80 & 0.74 & 0.84 & 0.80 \\
\hline
\end{tabular}

\section{Analysis of the dimensionality of the instrument (internal structure)}

In order to test for the internal consistency, we calculated the corrected correlation between the score of the item and the total CoRP. Coefficients were between 0.54 and 0.67 and were considered adequate since they were greater than 0.30 . Once again, we followed the recommendations of Fabrigar et al. (1999) in the exploratory factor analysis and performed a principal-axis factor analysis, using promax oblique method. Bartlett's sphericity test was equal to $X^{2}(d f=6, N=1061)=1434.562(p<0.001)$ and KMO index was 0.66 , indicating that correlation matrix was adequate. Considering the results from the factor analysis, corrected correlations of the items with the entire scale and the reliability analysis, we did not drop any items. Maximum Likelihood (ML) estimation was used considering eigenvalues greater than 1, and we established that an adequate single-factor solution could be found (Table 5).

Confirmatory factor analyses were conducted to ascertain the factor structure of the CoRP. Table 6 shows the single-factor structure: congeneric model, tau equivalent model, tau equivalent model with correlation between item 1 and 2 and item 3 and 4, and parallel model. The best fit indices were those of the equivalent tau model with the correlation of detection errors. The standardized regression coefficients weights of all variables loading onto the factor were between 0.50 and 0.88 , with all critical ratios above 1.96 (which means that all the regressions were statistically significant at the $95 \%$ confidence level).

\section{Discriminant validity}

The CoRP had a low correlation with the GHQ ( $r=0.14 ; \mathrm{p} \leq 0.000)$. 


\section{Crossover path analysis (test-retest)}

To examine the stability of the scale, we performed a crossover path analysis of the CoRP later in time, considering a reduced sample $(\mathrm{N}=46)$. We correlated the time points May $2020(\mathrm{t} 0)$ and June 2020 (t1). Results demonstrated that the initial results predicted those at the follow-up $(r=0.32 ; p=0.03)$.

\section{Testing for factor invariance}

Testing for the factor invariance of the CoRP scale required several steps. The first step was to perform preliminary confirmatory factor analyses, CFA model, in which single factor (tau equivalent with correlation between item 1 and 2 and item 3 and 4) was posited separately for young ( $18-35$ years; $\mathrm{N}=513$ ) and adult samples ( $36-80$ years; $\mathrm{N}=508)$. The model taken into account fitted the data well in each group: young: $X^{2}=6.21(3), p<0.001$; $\mathrm{CFI}=1.00 ; \mathrm{NFI}=0.99 ; \mathrm{RMSEA}=0.046(0.000$ 0.097); $\mathrm{SRMR}=0.026 ; \mathrm{AGFI}=0.98$; adult: $X^{2}=34.50$ (3), $p<0.001 ; \mathrm{CFI}=0.95 ; \mathrm{NFI}=0.94 ; \operatorname{RMSEA}=0.15(0.11 ; 0.20)$; $\mathrm{SRMR}=0.082 ; \mathrm{GFI}=0.96$. Multigroup CFAs were subsequently conducted with the aim to examine Metric Invariance (Thurstone, 1947). The model taken into account fitted the data well: $X^{2}=44.70(6), p<0.001 ; \mathrm{CFI}=0.97 ; \mathrm{NFI}=0.97$; RMSEA $=0.11(0.083 ; 0.14)$; $\mathrm{SRMR}=0.082 ; \mathrm{GFI}=0.96$. Standardized factor loadings of items were all significant. The coefficients have a value of 0.66 for young people and 0.68 for adults.

\section{Overall discussion and conclusion}

Governments and public health authorities urgently need guidance and actionable information on effective public health and psychological interventions that can safeguard the mental health of the general public in the COVID-19 pandemic (Rubin et al., 2020). Risk perception could be a key concept in the prevention of risky behavior and for effectively managing public health risks (Dryhurst et al., 2020). Given the importance of human psychological and behavioral factors in managing pandemics, it is crucial to assess psychological and behavioral responses to the situation to determine how perceived risk is linked to engagement in protective behaviors (Bish \& Michie, 2010). Considering the risk to the public that the COVID-19 poses, developing a brief and valid instrument to measure individuals' risk perception is both timely and important.

This study responded to the very call by identifying relevant content for standardized measures of risk perceptions and examining the structure, reliability, construct validity and invariance of the CoRP, a new measure that assesses people perceptions of the risk to COVID-19. The CoRP, although short, was found to be a robust assessment scale. Findings from the two studies demonstrated that CoRP has a stable unidimensional structure. Also, the scale had strong convergent and discriminant validity. Furthermore, our results contribute to an ongoing debate regarding the utility of short scales for measuring individual differences (Ziegler et al., 2014). The scale can be used to provide valuable information on how individuals perceive COVID-19 risk to institutions and healthcare providers who can design and further improve appropriate prevention programs.

Despite its contributions and the promising results, the present research has some limitations. Firstly, self-reported data could lead to common method variance issues and future 
studies should take a longitudinal approach to test the models more reliably over time. It would also be important to determine the associations of the scale with non-self-report assessments, and to include actual behavioral measures. The tests for validity were carried out on convenience samples and future research should test whether this result is reproducible in a representative sample. Self-report instruments have the potential for issues of social desirability bias. Although we need to consider this limitation, it is reasonable to think that our data are not highly influenced by this bias because anonymity was guaranteed in data collection (Roccato, 2006).

Based on the strong psychometric properties of the scale, we recommend a wide use of the CoRP in COVID-19 research and health interventions. The scale should also be tested and validated in languages other than Italian for usage across cultures. Governments and public health authorities around the globe should pay a closer attention to the role of risk perception at the individual level in more effectively managing policies and interventions around COVID-19, and for this purpose, we believe the CoRP can prove to be a useful tool.

Funding Open access funding provided by Universita degli Studi di Napoli Federico II within the CRUICARE Agreement.

\section{Declarations}

Ethics approval and consent to participate All procedures followed were in accordance with the ethical standards of the responsible committee on human experimentation (institutional and national) and with the Helsinki Declaration of 1975, as revised in 2000. Informed consent was obtained from all participants for being included in the study.

Conflict of interest The authors declare no competing of interests.

Open Access This article is licensed under a Creative Commons Attribution 4.0 International License, which permits use, sharing, adaptation, distribution and reproduction in any medium or format, as long as you give appropriate credit to the original author(s) and the source, provide a link to the Creative Commons licence, and indicate if changes were made. The images or other third party material in this article are included in the article's Creative Commons licence, unless indicated otherwise in a credit line to the material. If material is not included in the article's Creative Commons licence and your intended use is not permitted by statutory regulation or exceeds the permitted use, you will need to obtain permission directly from the copyright holder. To view a copy of this licence, visit http://creativecommons.org/licenses/by/4.0/.

\section{References}

Ahorsu D.K., Lin C.-Y., Imani V., Saffari M., Griffiths M.D., Pakpour A.H. (2020). The Fear of COVID-19 Scale: Development and initial validation. International Journal of Mental Health and Addiction, 1-9. https://doi.org/10.1007/s11469-020-00270-8

Baldwin, C., Cave, B., \& Rawstorne, P. (2020). Measuring the impact of public understandings of riskfrom urban and industrial development on community psychosocial well-being: A mixed methods strategy. International Journal of Community Well-Being, 3, 57-82. https://doi.org/10.1007/ s42413-019-00041-X

Bentler, P. M. (2005). EQS 6.1. Encino, CA: Multivariate Software, Inc.

Birley, M. 2015. Social determinants of risk perception. Paper presented at the annual meeting for the Society of International Association for Impact Assessment (IAIA15), Florence, 20 - 23 April 2015. 
Bish, A., \& Michie, S. (2010). Demographic and attitudinal determinants of protective behaviours during a pandemic: A review. British Journal of Health Psychology, 15(4), 797-824. https://doi.org/10.1348/ $135910710 \mathrm{X} 485826$

Brewer, N. T., Chapman, G. B., Gibbons, F. X., Gerrard, M., McCaul, K. D., \& Weinstein, N. D. (2007). Meta-analysis of the relationship between risk perception and health behavior: The example of vaccination. Health Psychology, 26(2), 136-145. https://doi.org/10.1037/0278-6133.26.2.136

Byrne, B. M. (1994). Structural equation modeling with EQS and EQS/Windows. Sage Publications.

Capone, V., \& Petrillo, G. (2010). Smettere di fumare in adolescenza: Il ruolo delle intenzioni, della pianificazione e delle percezioni di autoefficacia nell'HAPA Model. Psicologia Della Salute, 3, 45-63. https://doi.org/10.3280/PDS2010-003004

Capone, V., \& Petrillo, G. (2012). Costruzione e validazione della Health Profession Communication Collective Efficacy Scale. Giornale Italiano Di Psicologia, 4, 903-930. https://doi.org/10.1421/73148

Capone, V., Caso, D., Donizzetti, A. R., \& Procentese, F. (2020). University student mental well-being during COVID-19 outbreak: What are the relationships between information seeking, perceived risk and personal resources related to the academic context? Sustainability, 12(17), 7039. https://doi.org/10. 3390/su12177039

Caserotti, M., Girardi, P., Rubaltelli, E., Tasso, A., Lotto, L., \& Gavaruzzi, T. (2021). Associations of COVID-19 risk perception with vaccine hesitancy over time for Italian residents. Social Science \& Medicine, 272, 113688.

Cori, L., Bianchi, F., Cadum, E., \& Anthonj, C. (2020). Risk perception and COVID-19. International Journal of Environmental Research and Public Health, 17, 3114. https://doi.org/10.3390/ijerph17093114

Dai, Y., Hu, G., Xiong, H., Qiu, H., \& Yuan, X. (2020). Psychological impact of the coronavirus disease 2019 (COVID-19) outbreak on healthcare workers in China. medRxiv, March 06. https://doi.org/10. 1101/2020.03.03.20030874

Davico, C., Ghiggia, A., Marcotulli, D., Ricci, F., Amianto, F., \& Vitiello, B. (2020). Psychological impact of the COVID-19 pandemic on adults and their children in Italy. The Lancet Psychiatry, May 05. https://doi.org/10.2139/ssrn.3576933

DeVellis, R. (2003). Scale development: Theory and applications. Sage Publications.

Donizzetti, A. R. (2009). La percezione del rischio in adolescenza: Costruzione e validazione di strumenti di rilevazione. Psicologia Della Salute, 2, 145-162. https://doi.org/10.3280/PDS20 09-002010

Dryhurst S., Schneider, C. R., Kerr, J., Freeman, A. L. J., Recchia, G., van der Bles, A. M., Spiegelhalter, D., \& van der Linden, S. (2020). Risk perceptions of COVID-19 around the world. Journal of Risk Research, May 05. doi:https://doi.org/10.1080/13669877.2020.1758193

Fabrigar, L. R., Wegener, D. T., MacCallum, R. C., \& Strahan, E. J. (1999). Evaluating the use of exploratory factor analysis in psychological research. Psychological Methods, 4(3), 272-299. https://doi. org/10.1037/1082-989X.4.3.272

Flesia, L., Monaro, M., Mazza, C., Fietta, V., Colicino, E., Segatto, B., \& Roma, P. (2020). Predicting perceived stress related to the Covid-19 outbreak through stable psychological traits and machine learning models. Journal of Clinical Medicine., 9(10), 3350. https://doi.org/10.3390/jcm9103350

Floyd, D. L., Prentice-Dunn, S., \& Rogers, R. W. (2000). A meta-analysis of research on protection motivation theory. Journal of Applied Social Psychology, 30(2), 407-429. https://doi.org/10.1111/j. 1559-1816.2000.tb02323.x

Gerhold, L. (2020). COVID-19: Risk perception and coping strategies. PsyArXiv, 25 March. https://doi. org/10.31234/osf.io/xmpk4

Giorgi, G., Perez, F. S. F., D’Antonio, A., Mucci, N., Ferrero, C., Cupelli, V., \& Arcangeli, G. (2015). Psychometric properties of the Impact of Event Scale-6 in a sample of victims of bank robbery. Psychology Research and Behavior Management, 8, 99-104. https://doi.org/10.2147/PRBM. S73901

Goldberg, D. (1992). General Health Questionnaire (GHQ-12). Windsor, UK: NFER-Nelson.

Graffigna, G., Barello, S., Savarese, M., Palamenghi, L., Castellini, G., Bonanomi, A., \& Lozza, E. (2020). Measuring Italian citizens' engagement in the first wave of the COVID-19 pandemic containment measures a cross-sectional study. medRxiv [preprint], April 25. https://doi.org/10.1101/ 2020.04.22.20075234

Hershey, J. C., Asch, D. A., Thumasathit, T., Meszaros, J., \& Waters, V. V. (1994). The roles of altruism, free riding, and bandwagoning in vaccination decisions. Organizational Behavior and Human Decision Processes, 59(2), 177-187. https://doi.org/10.1006/obhd.1994.1055

Hu, L., \& Bentler, P. M. (1999). Cutoff criteria for fit indexes in covariance structure analysis: Conventional criteria versus new alternatives. Structural Equation Modeling: A Multidisciplinary Journal, 6, 1-55. https://doi.org/10.1080/10705519909540118 
Huynh, T. L. D. (2020). Data for understanding the risk perception of COVID-19 from Vietnamese sample. Data in Brief, 30 (105530). https://doi.org/10.1016/j.dib.2020.105530

Lerner, J. S., \& Keltner, D. (2001). Fear, anger, and risk. Journal of Personality and Social Psychology, 81(1), 146-159. https://doi.org/10.1037/0022-3514.81.1.146

Li, S., Wang, Y., Xue, J., Zhao, N., \& Zhu, T. (2020). The impact of COVID-19 epidemic declaration on psychological consequences: A study on active Weibo users. International Journal of Environmental Research and Public Health, 17(6), 2032. https://doi.org/10.3390/ijerph17062032

van der Linden, S. (2017). Determinants and Measurement of Climate Change Risk Perception, Worry, and Concern. In Oxford Encyclopedia of Climate Change Communication, edited by M. C. Nisbet, M. Schafer, E. Markowitz, S. Ho, S. O’Neill, and J. Thaker. Oxford, UK: The Oxford University Press. https://doi.org/10.2139/ssrn.2953631

Loewenstein, G. F., Weber, E. U., Hsee, C. K., \& Welch, N. (2001). Risk as feelings. Psychological Bulletin, 127(2), 267-286. https://doi.org/10.1037/0033-2909.127.2.267

Nunnally, J. C., \& Bernstein, I. J. (1994). Psychometric theory. McGraw-Hill.

Nunnally, J. C., \& Bernstein, I. J. (1995). Teoría psicométrica (3 ${ }^{\mathrm{a}}$ ed). México, D.F.: Editorial McGrawHill Latinoamericana.

Pappas, G., Kiriaze, I. J., Giannakis, P., \& Falagas, M. E. (2009). Psychosocial consequences of infectious diseases. Clinical Microbiology and Infection, 15(8), 743-747. https://doi.org/10.1111/j. 1469-0691.2009.02947.x

Piccinelli, M., \& Politi, P. (1993). Struttura fattoriale della versione a 12 domande del General Health Questionnaire in un campione di giovani maschi adulti. Epidemiology and Psychiatric Sciences, 2(3), 173-181. https://doi.org/10.1017/S1121189X00006990

Roccato, M. (2006). L'inchiesta e il sondaggio nella ricerca psicosociale. Bologna, IT: Il Mulino.

Rohrmann, B., \& Renn, O. (2000). Risk perception research. An introduction. In O. Renn \& B. Rohrmann (Eds.), Cross-cultural risk perception. A survey of empirical studies (pp. 11-15). Springer.

Rubin, E. J., Baden, L. R., Morrissey, S., \& Campion, E. W. (2020). Medical journals and the 2019-nCoV outbreak. The New England Journal of Medicine, 382, 866. https://doi.org/10.1056/NEJMe2001329

Ruiu, M. L. (2020). Mismanagement of Covid-19: lessons learned from Italy. Journal of Risk Research, May 06. https://doi.org/10.1080/13669877.2020.1758755

Schwarz, N., \& Clore, G. L. (1983). Mood, misattribution, and judgments of well-being: Informative and directive functions of affective states. Journal of Personality and Social Psychology, 45, 513-523.

Shabu, S., Amen, K. M., Mahmood, K. I., \& Shabila, N. P. (2020). Risk perception and behavioral response to COVID-19 in Iraqi Kurdistan Region. BMC Infectious Diseases, April 12. https://doi.org/10.21203/ rs.3.rs-22025/v1

Sjöberg, L. (2000). The Methodology of Risk Perception Research. Quality and Quantity, 34(4), 407-418. https://doi.org/10.1023/A:1004838806793

Sjöberg, L., Moen, B., \& Rundmo, T. (2004). Explaining risk perception. An evaluation of the psychometric paradigm in risk perception research. Rotunde publikasjoner Rotunde, 84, 55-76. Available from: http://www.svt.ntnu.no/psy/Torbjorn.Rundmo/Psychometric_paradigm.pdf

Slovic, P. (1992). Perception of risk: Reflections on the psychometric paradigm. In S. Krimsky \& D. Golding (Eds.), Social theories of risk (pp. 117-152). Praeger.

Slovic, P. (2000). Perception of Risk. Earthscan.

Slovic, P., \& Peters, E. (2006). Risk perception and affect. Current Directions in Psychological Science, 15(6), 322-325.

Steyer, R. (2001). Classical (Psychometric) Test Theory. In T. Cook \& C. Ragin (Eds.), International encyclopedia of the social and behavioral sciences: Logic of inquiry and research design (pp. 1955-1962). Pergamon.

Thurstone, L. L. (1947). Multiple factor analysis. University of Chicago Press.

Traub, R. E. (1994). Reliability for the social sciences: Theory and applications. SAGE Publications, Inc.

WHO (2020a). WHO Director-General's opening remarks at the media briefing on COVID-19 - 11 March 2020. Accessed March 11. https://www.who.int/dg/speeches/detail/who-director-general-s-openingremarks-at-the-media-briefing-on-covid-19-11-march-2020

WHO (2020b). Coronavirus disease (COVID-19) advice for the public. Accessed April 29. https://www. who.int/emergencies/diseases/novel-coronavirus-2019/advice-for-public

Wise, T., Zbozinek, T. D., Michelini, G., \& Hagan, C. C. (2020). Changes in risk perception and protective behavior during the first week of the COVID-19 pandemic in the United States. PsyArXiv, March 19. https://doi.org/10.31234/osf.io/dz428

Zani, B., \& Cicognani E. (2000). Psicologia della salute. Bologna, IT: Il Mulino. 
Ziegler, M., Kemper, C. J., \& Kruyen, P. (2014). Short scales - Five misunderstandings and ways to overcome them. Journal of Individual Differences, 35(4), 185-189. https://doi.org/10.1027/1614-0001/ a000148

Publisher's Note Springer Nature remains neutral with regard to jurisdictional claims in published maps and institutional affiliations. 